$5-1-2020$

\title{
Guatemala indigenous municipalities: COVID-19 knowledge, attitudes, and practices
}

Population Council

Follow this and additional works at: https://knowledgecommons.popcouncil.org/departments_sbsr-pgy

Part of the International Public Health Commons, and the Social and Behavioral Sciences Commons How does access to this work benefit you? Let us know!

\section{Recommended Citation}

"Guatemala indigenous municipalities: COVID-19 knowledge, attitudes, and practices," COVID-19 Research \& Evaluations presentation. Guatemala City: Population Council, 2020.

This Presentation is brought to you for free and open access by the Population Council. 


\section{POPULATION}

\section{COUNCIL}

Ideas. Evidence. Impact.

\section{GUATEMALA INDIGENOUS}

MUNICIPALITIES: COVID-19

KNOWLEDGE, ATTITUDES, AND

PRACTICES

Population Council Guatemala

May 1, 2020 


\section{Overview (1)}

- Indigenous population prioritized because of its vulnerability to COVID-19 due to social and economic marginalization

- Phone-based key informant interviews conducted April $14-18$

- 10 indigenous municipalities: Chisec, Patzún, San Andrés Semetabaj, San Juan Ostuncalco, San Juan Sacatepéquez, San Pedro Carchá, Santa María Chiquimula, Sololá, Totonicapán, and Uspantán

- 144 interviews completed

- $87.8 \%$ participation rate in interviews

- $98 \%$ of informants willing to participate in future rounds 


\section{Overview (2)}

- Groups of key informants selected on long-standing partnerships with indigenous municipalities with the following profiles:

- Heads of household (mostly female)

- First respondents at the community level

- Young indigenous women trained as mentors in Population Council programs

- Municipal and health workers

- 72\% female

- Mean age: 38 years (range 18-70)

- $100 \%$ awareness of COVID-19 


\section{Key Informant Groups ( $=144)$}

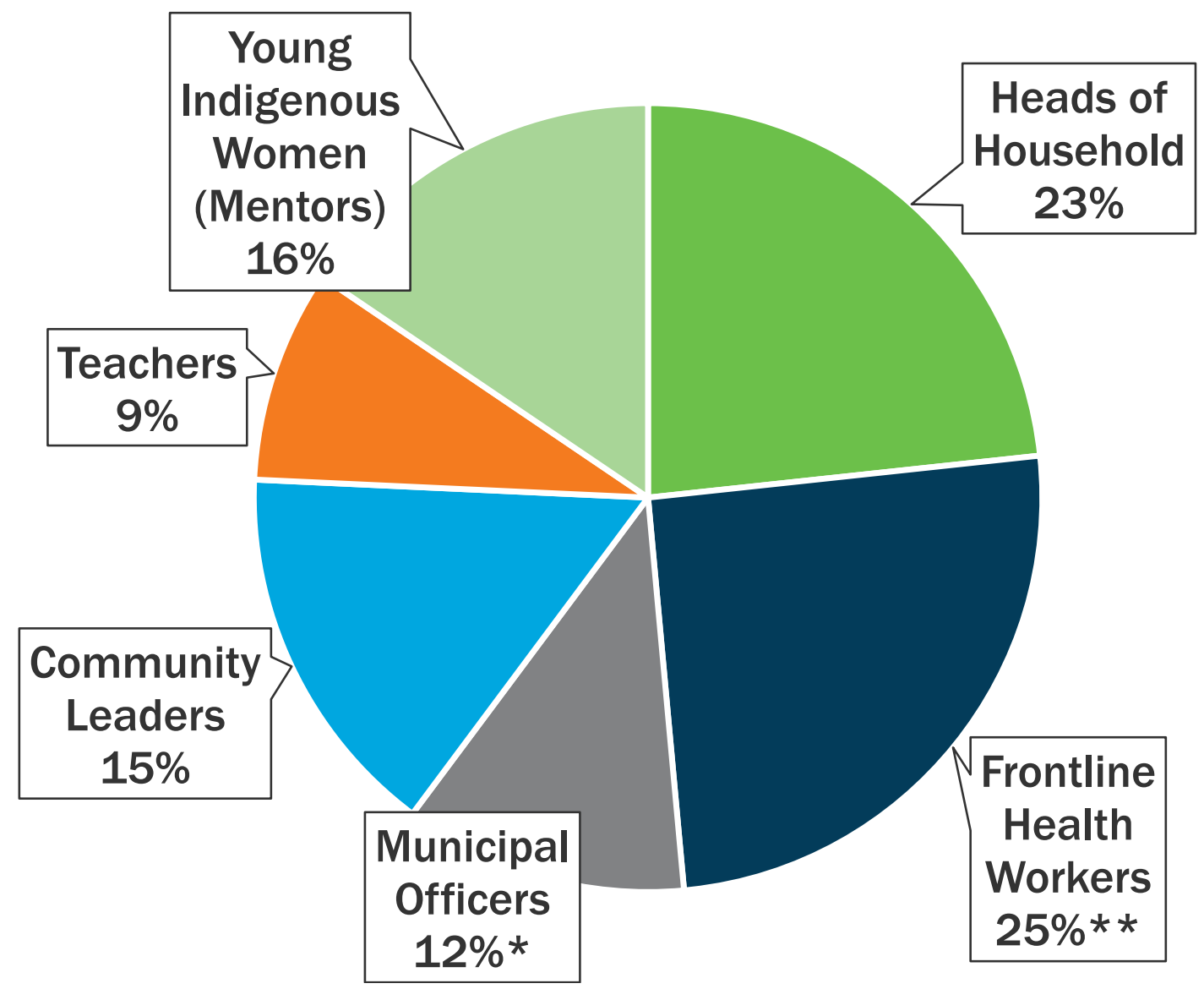

* * Midwives, Community Health Promoters, and Clinic Health Workers

*Offices for Youth and Women 


\section{Who can be infected with Coronavirus?}

100

90

More teachers reported that

80

74

children can be infected (85\%)

but had lower awareness that

anyone can be infected (8\%)

60

50

40

30

27

20

10

0

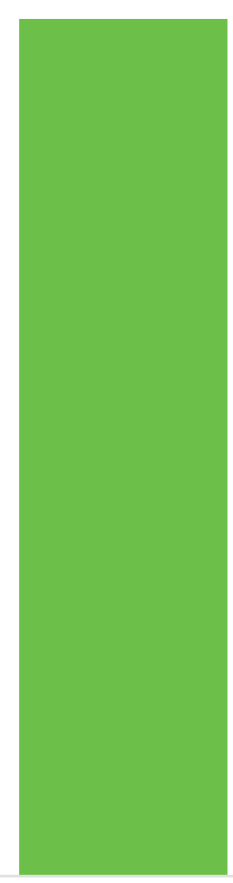

19
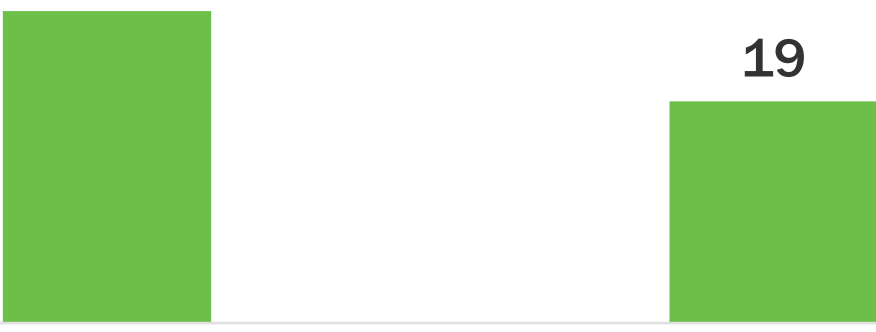

Anybody

Elderly

Children 


\section{Who is at high risk of severe illness if they get COVID-19?}

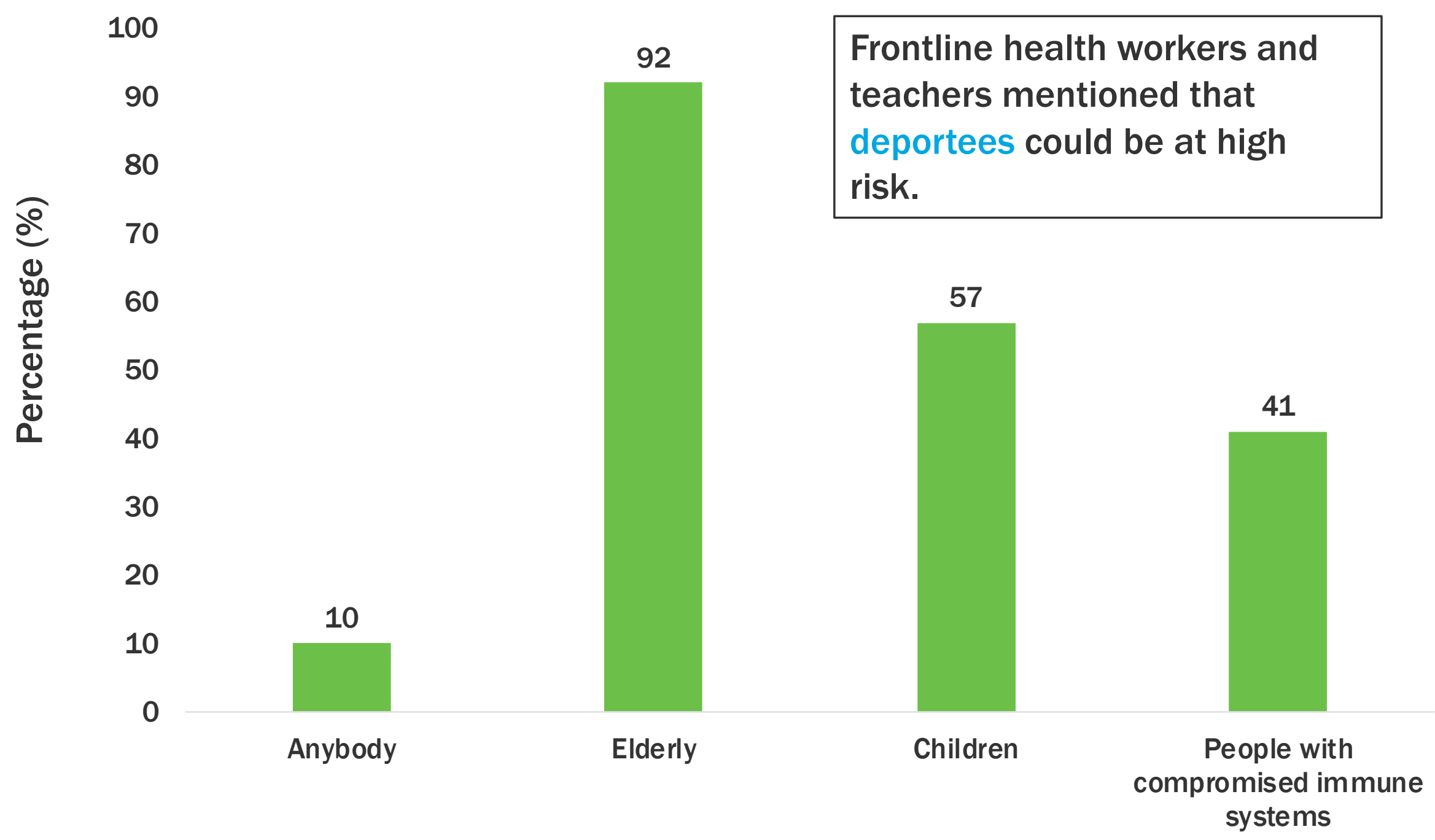




\section{What are the symptoms of COVID-19?}

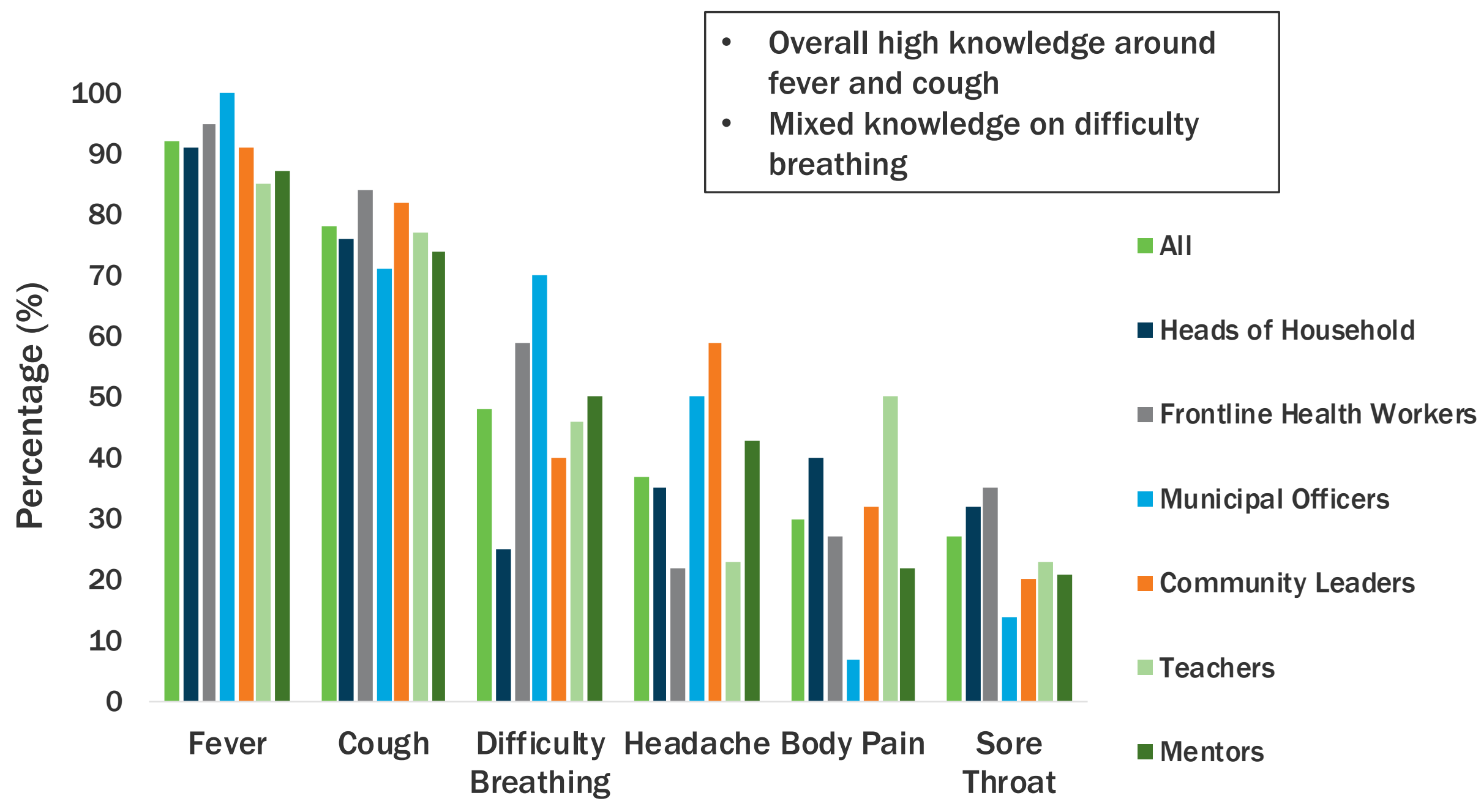

Symptoms 


\section{How can infection be prevented?}

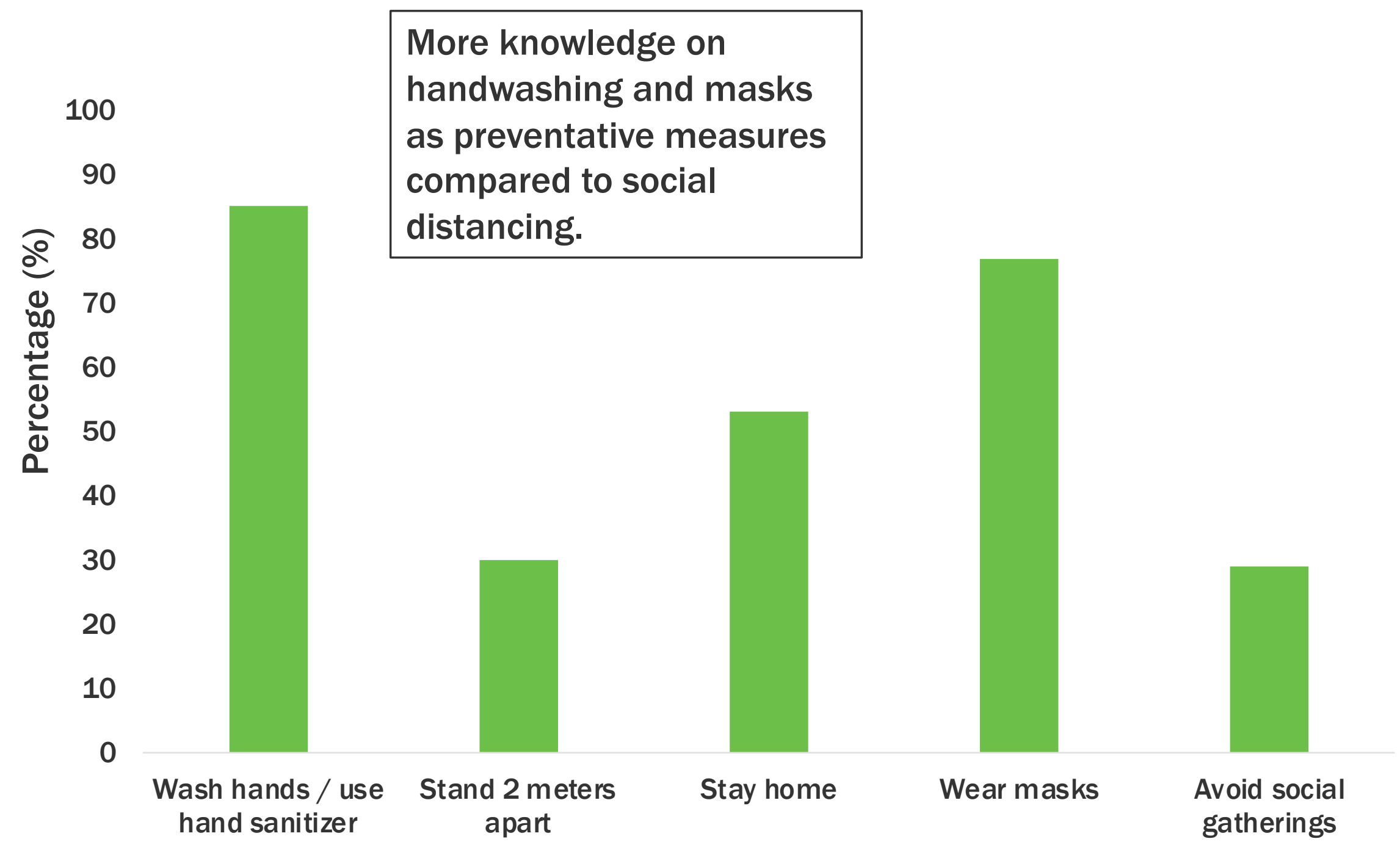




\section{My chances of getting infected with}

COVID-19 are:

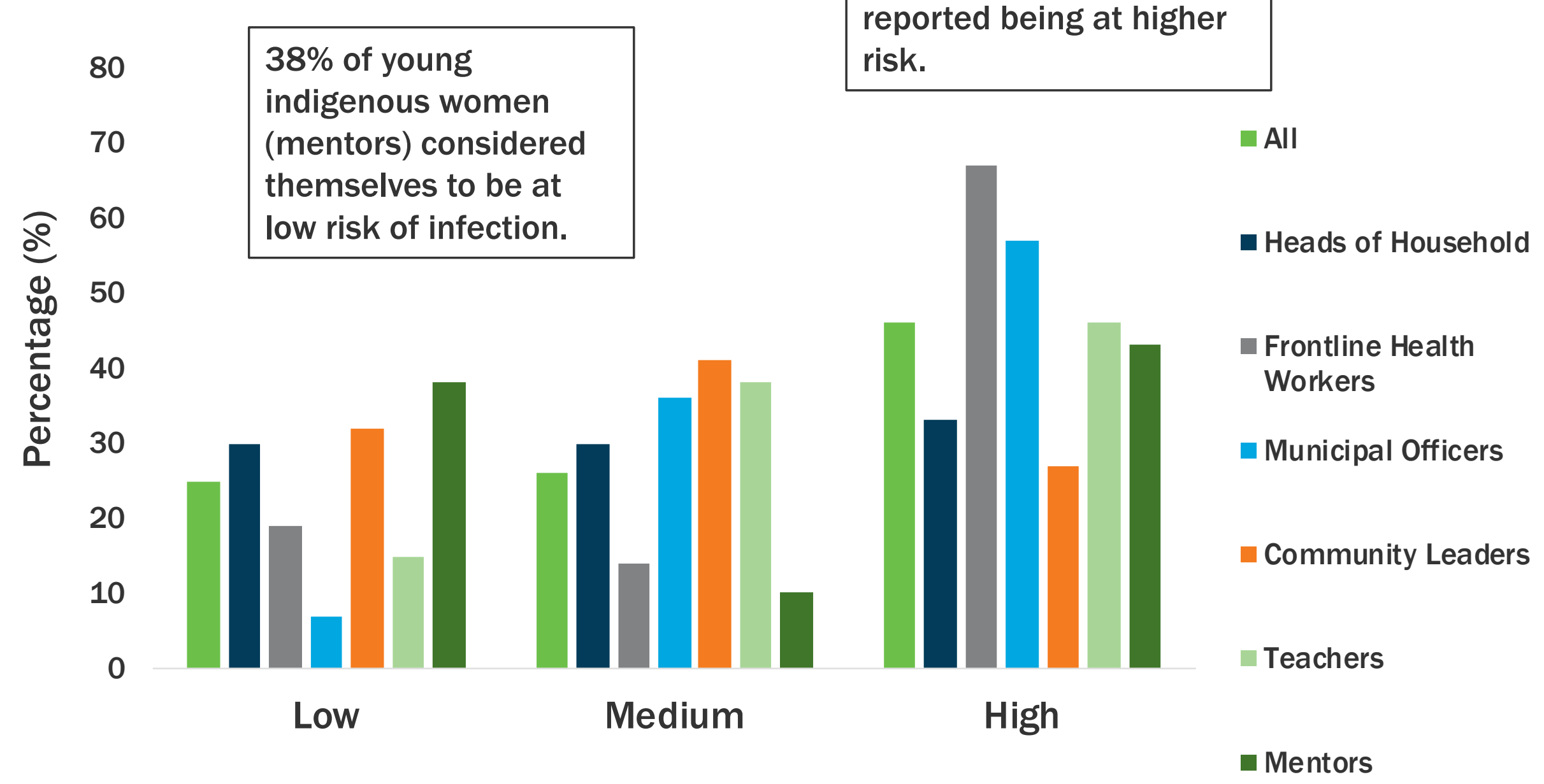

More frontline health workers (67\%) and municipal officers (57\%) reported being at higher risk.

Frontline Health Workers

Municipal Officers 


\section{Why do you think you are at low risk or not at risk of getting COVID-19?}

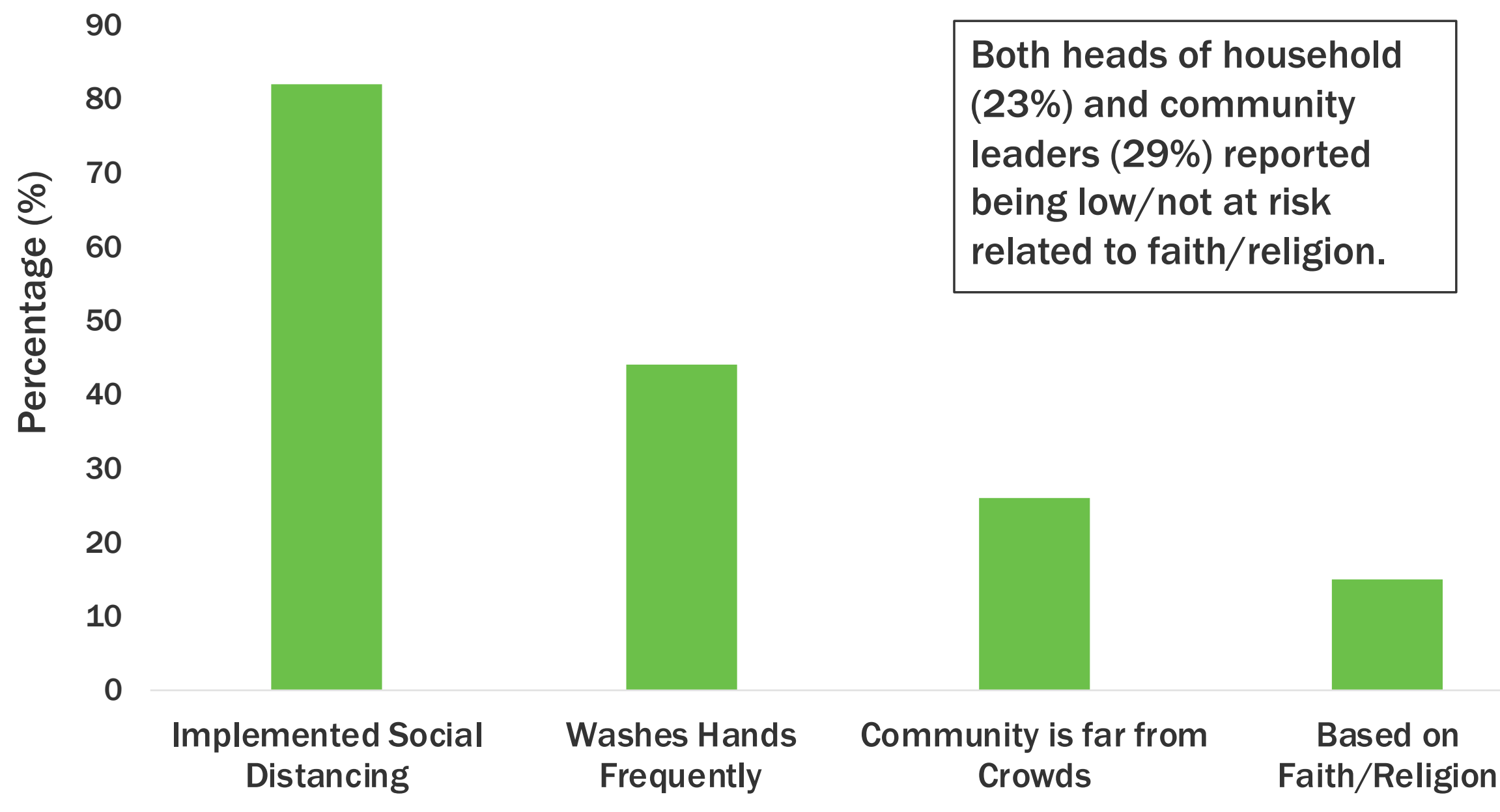




\section{Of the sources you use for information, which do you trust the most for COVID-19 information?}

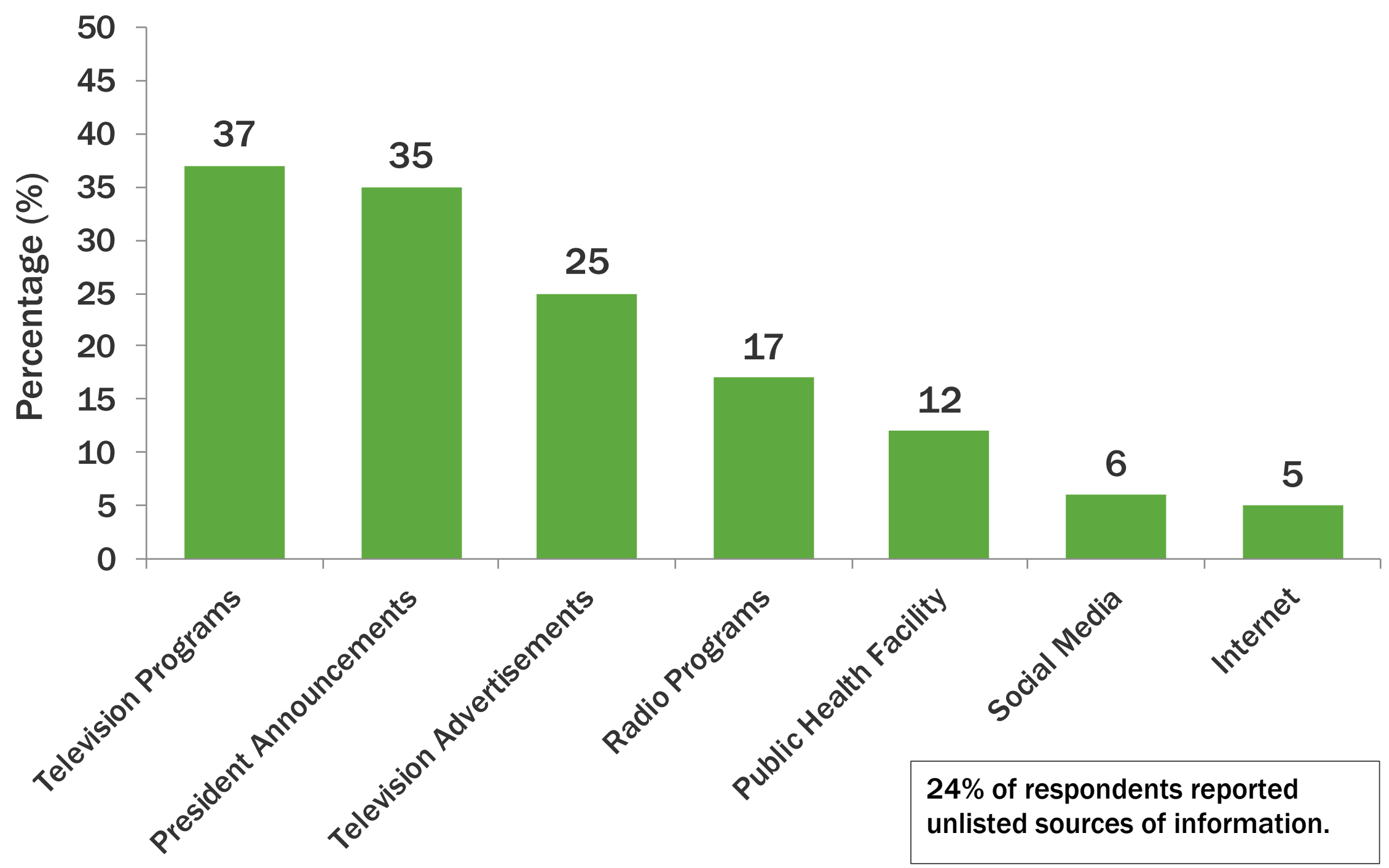




\section{What are your main fears regarding COVID-19?}

100

90

All

80

- Heads of Household

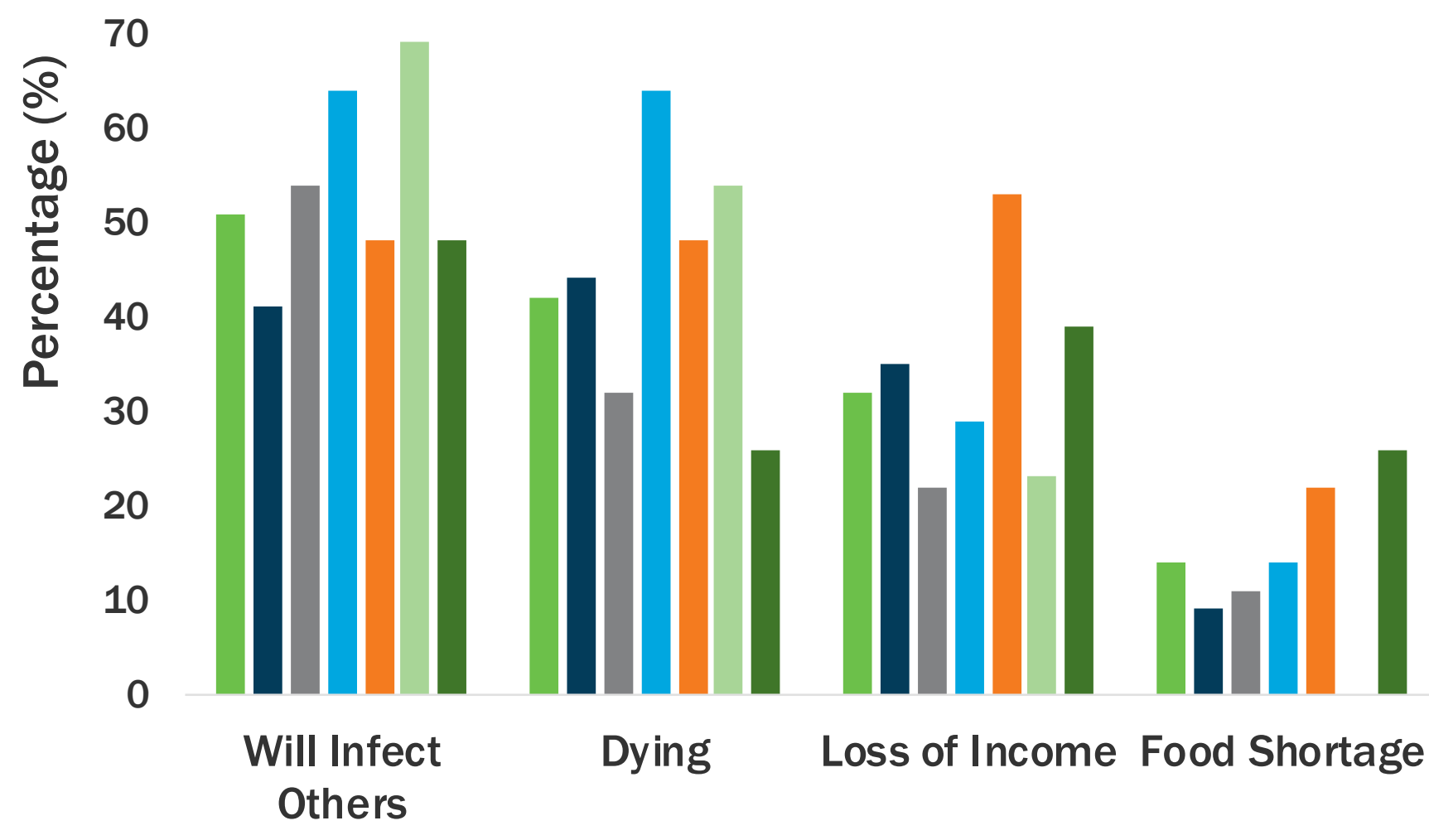

Frontline Health Workers

Municipal Officers

Community Leaders

Teachers

Mentors

Others 


\section{The government's reaction to the current COVID-19 outbreak is:}

A majority (81\%) of respondents think that the government has been either somewhat or very truthful about the COVID-19 outbreak.

100

90

80

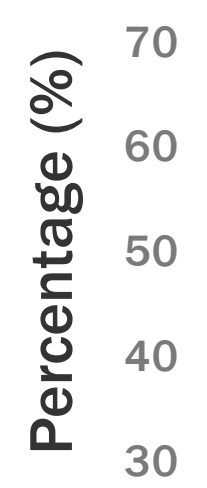

30

20

10

0

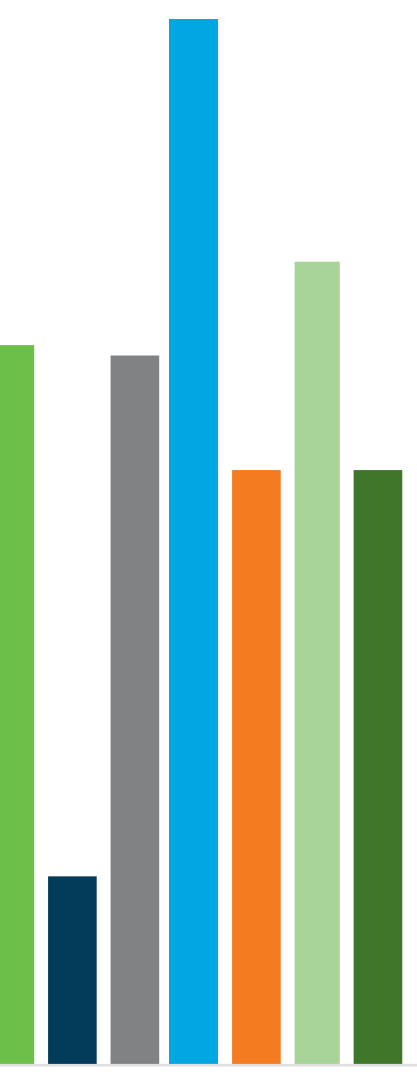

Somewhat too

extreme Appropriate

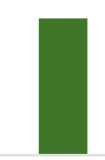
Appropriate 


\section{What activities have you done more in this past week compared to a month ago?}

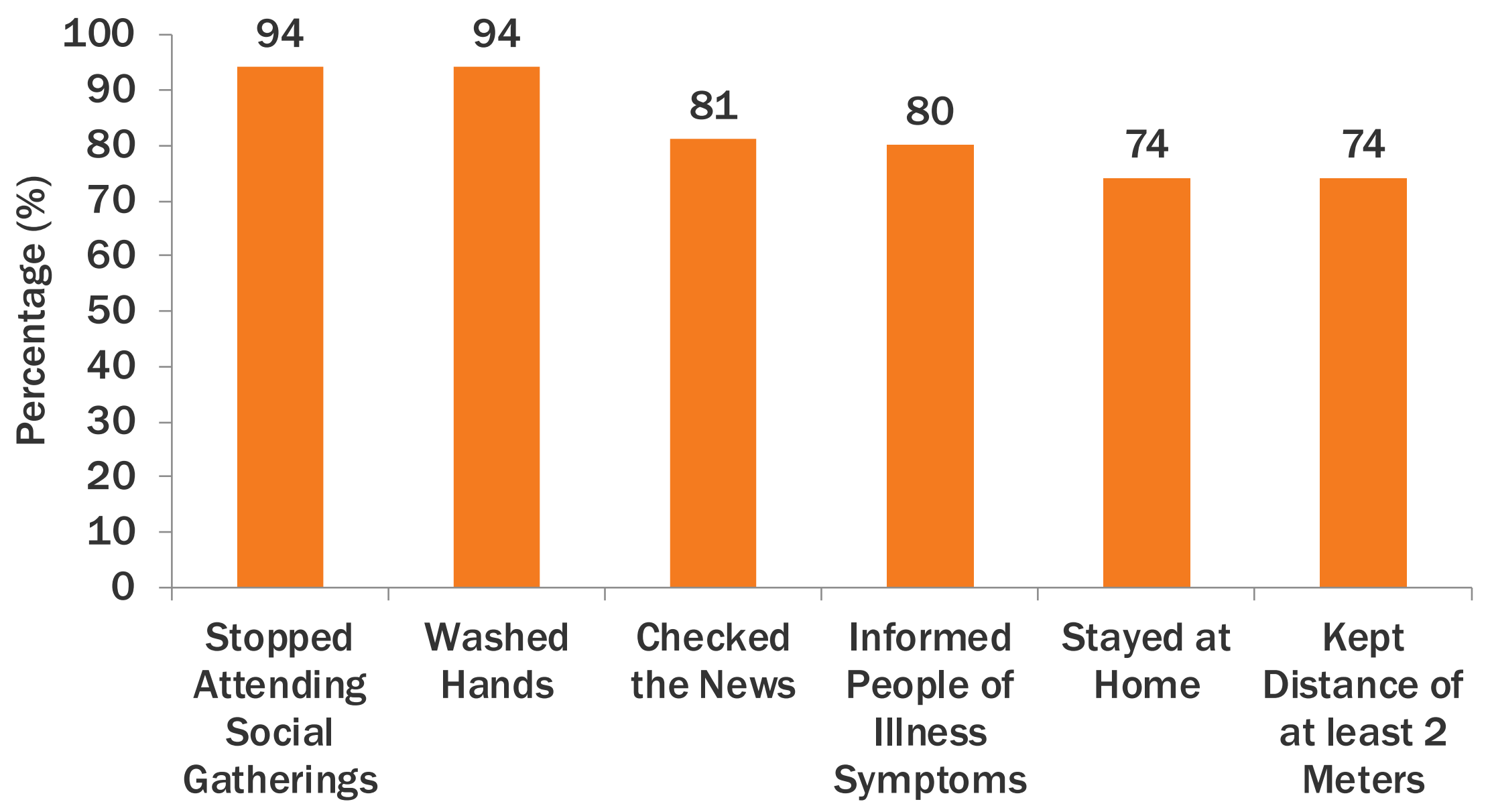




\section{Groups that have stayed at home more in this past week compared to a month ago:}

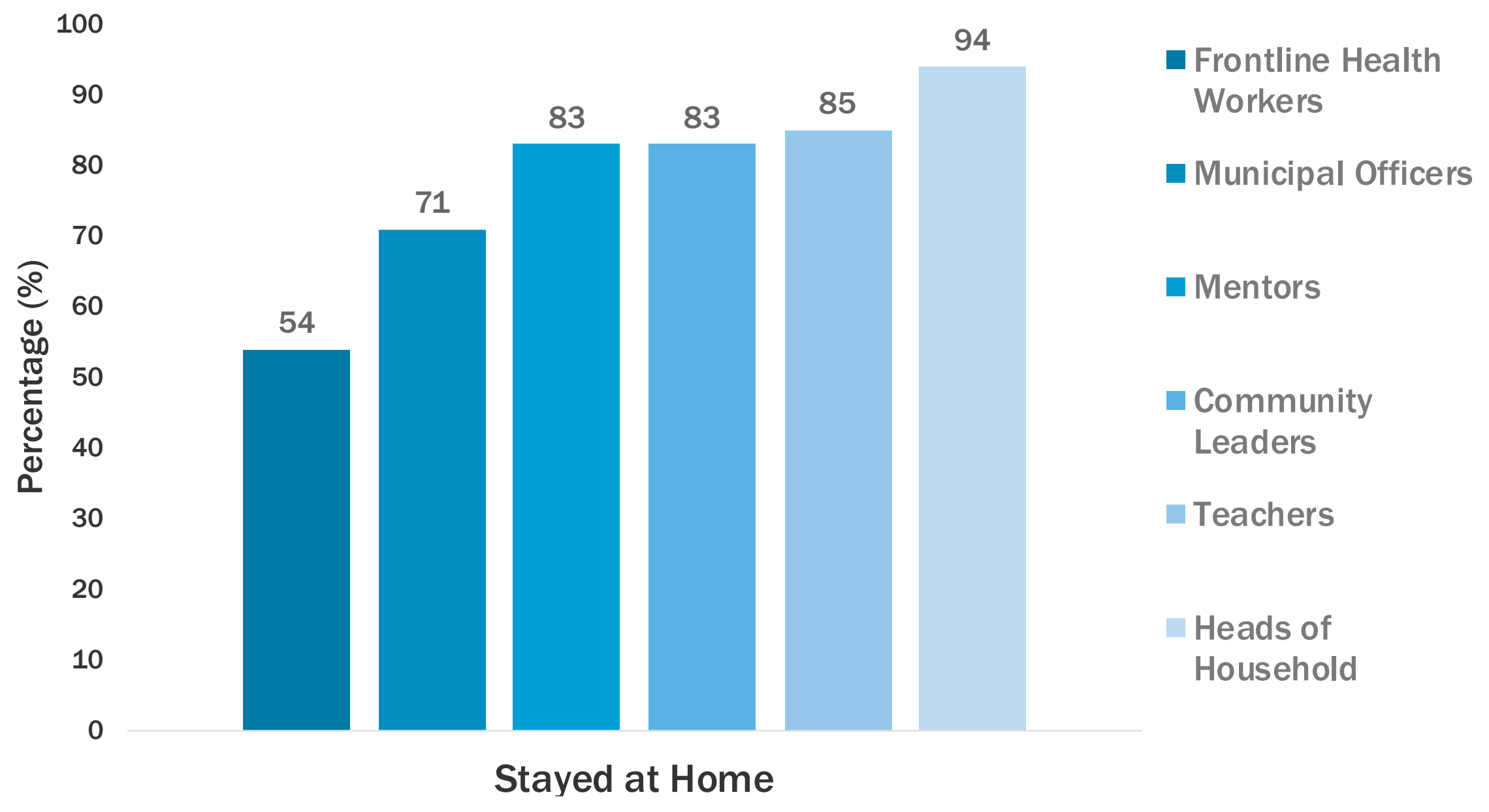




\section{If you had symptoms of COVID-19, what would you do?}

100

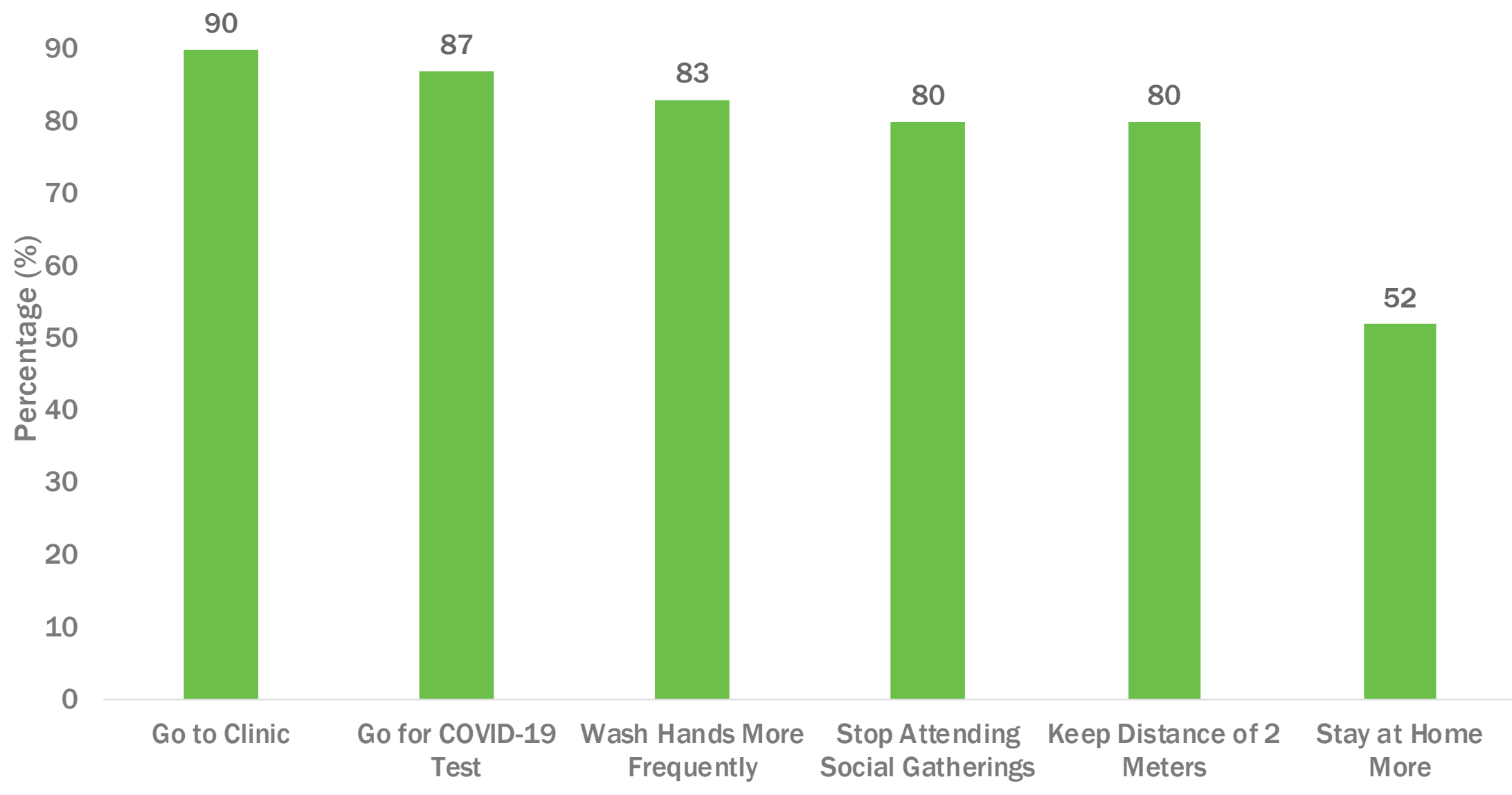




\section{What are your community's challenges to self-isolating?}

60

50

$56 \%$ of informants think that fellow community members would be able to stay at home for 14 days if asked. 


\section{What are your community's challenges to frequent handwashing or using hand sanitizers?}

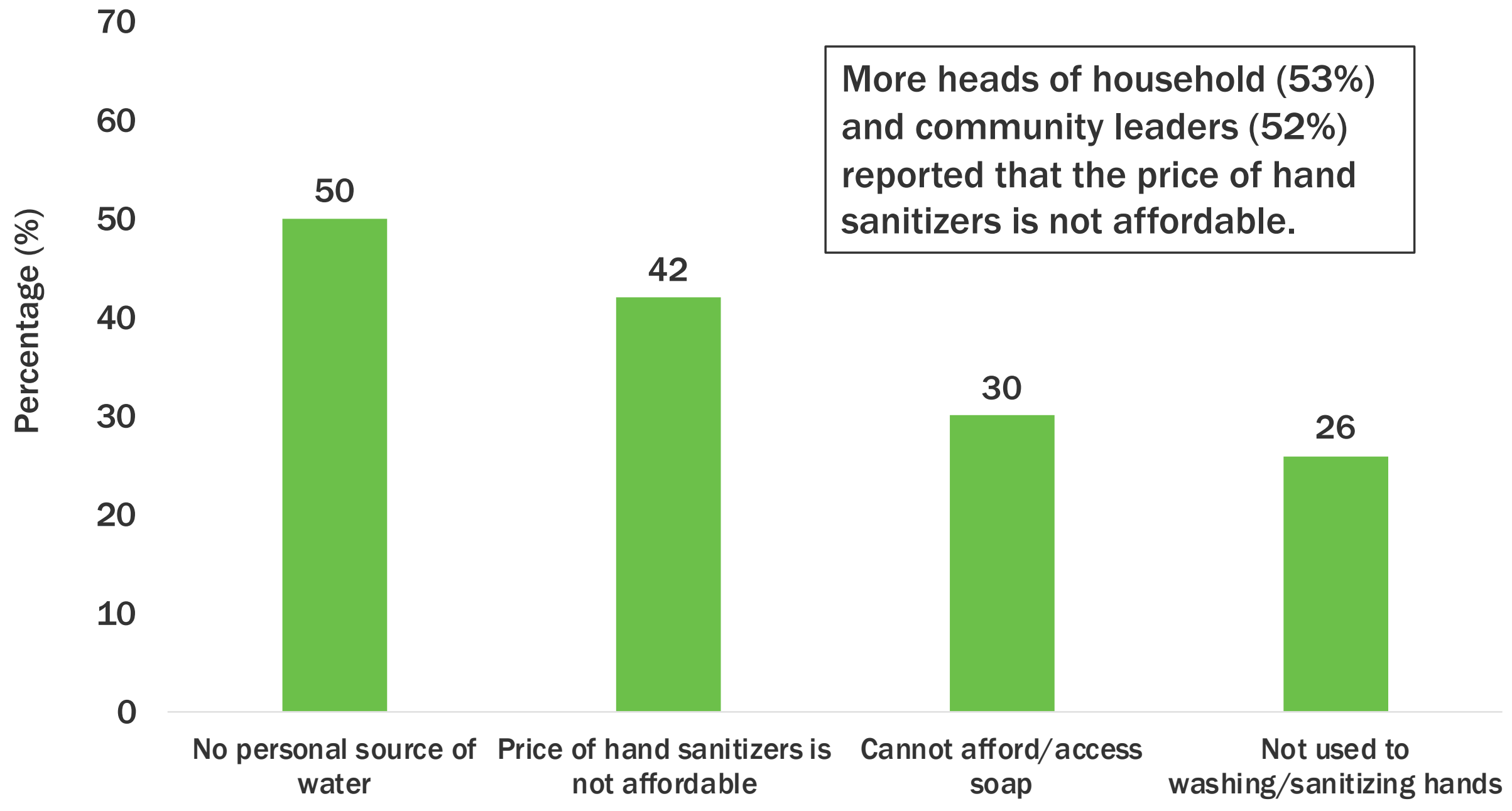




\section{If you were told by the government to stay in your house for the next two weeks, what would your critical needs be?}

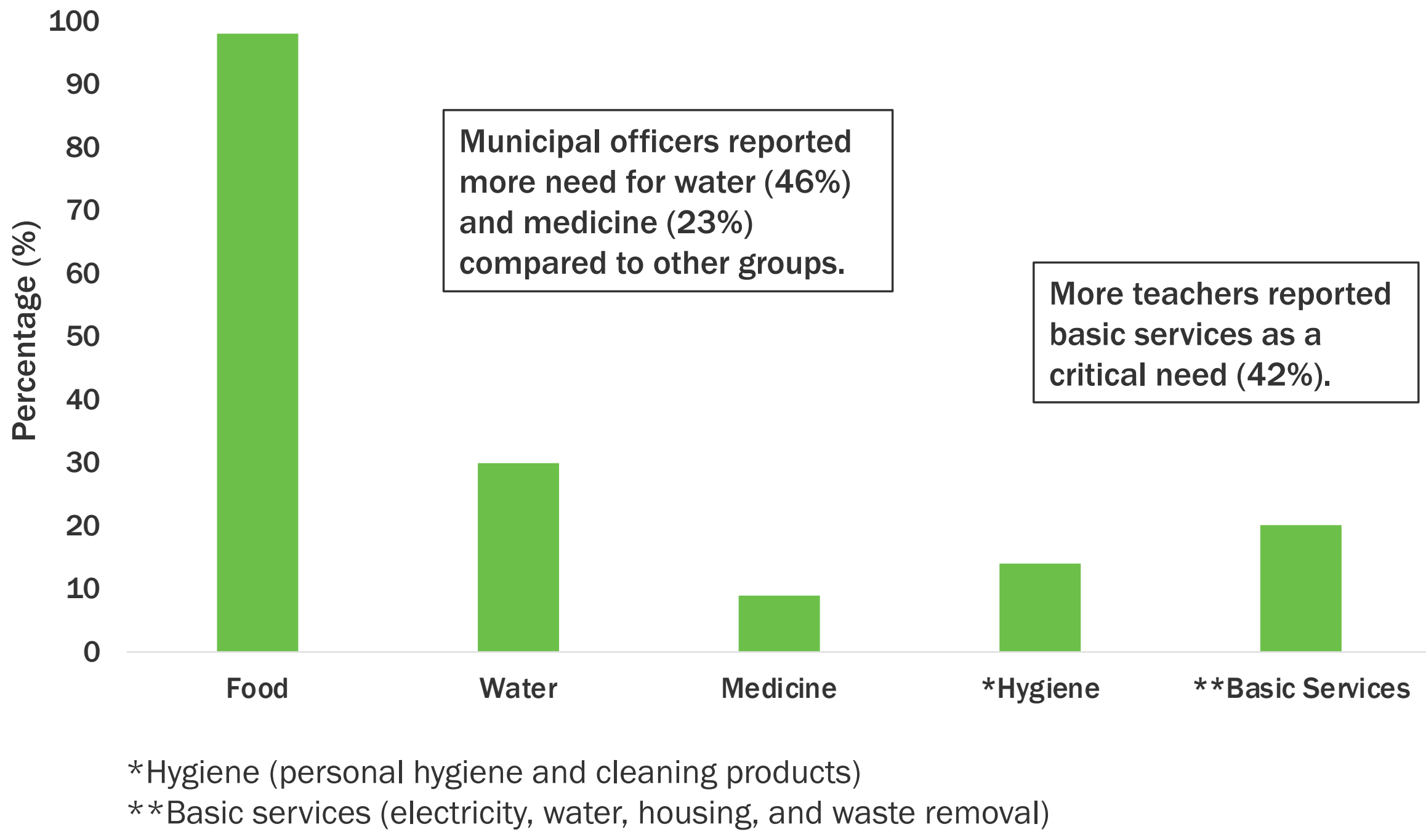




\section{Recommendations:}

\section{Knowledge and Perceptions}

- The Government of Guatemala should intensify efforts to deliver accurate information on the prevention of COVID19 to indigenous communities with a focus on:

- Developing a COVID-19 road map for community action after the first case is identified in a given municipality, considering alternatives for self-isolation for poorest households.

- Conveying tailored, actionable information with a multilingual approach.

- Engaging and mobilizing community leaders, teachers, midwives, and young indigenous female mentors to deliver information at the community and household levels. 


\section{Recommendations: \\ Government Emergency Plans}

- Support frontline health workers and municipal officers who say they are at high risk and are not able to stay at home due to their profesión by providing personal protective equipment.

- Central and municipal government should intensify efforts to address the impact of food insecurity and loss of income, and guarantee indigenous communities access to hygiene products and medicine. 


\section{Contact information:}

\section{Angel del Valle, adelvalle@popcouncil.org}

Corinne White, cwhite@popcouncil.org

Partnering with national health ministries and other government agencies in sub-Saharan Africa, South Asia, and Latin America, Population Council global and in-country scientists are conducting COVID-19 public health and social science research to produce relevant and timely evidence to support policymakers in controlling the spread of coronavirus, evaluating the effectiveness of prevention and mitigation measures, and assessing the longer-term health, social, and economic effects of the pandemic.

Suggested citation: "Guatemala Indigenous Municipalities: COVID-19 Knowledge, Attitudes, and Practices." COVID-19 Research and Evaluations Project. 2020. Guatemala: Population Council.

(C) 2020 The Population Council, Inc. 